\title{
The Degree of Contribution of Patterns of Mothers' Treatment to the Emotional Balance of Kindergarten Children
}

\author{
Sami Salamah Al-Massarweh ${ }^{1}$, Moham'd M. AL-Dlalah ${ }^{2}$, Abdelraouf Hameed Alyamani ${ }^{2} \&$ Safia M. Jabali $^{2}$ \\ ${ }^{1}$ Department of Psychology, Arts Faculty, Isra University, Jordan \\ ${ }^{2}$ Faculty of Educational Sciences, Isra University, Jordan \\ Correspondence: Sami Salamah Al-Massarweh, Department of Psychology, Arts Faculty, Isra University, Jordan.
}

Received: June 10, $2021 \quad$ Accepted: January 18, $2022 \quad$ Online Published: February 4, 2022

doi:10.5539/jel.v11n2p76 URL: https://doi.org/10.5539/jel.v11n2p76

\begin{abstract}
This study aimed to identify the degree of contribution of mothers' treatment patterns to the emotional balance of kindergarten children and to achieve the objectives of the study; two scales were built: a questionnaire to measure mothers' treatment patterns and a questionnaire to measure the emotional balance of kindergarten children after ensuring their validity and reliability. The study sample consisted of 195 children aged 5-6 who were selected from the private kindergartens of the Naour Brigade in Amman Governorate in Jordan. After using arithmetic means, standard deviations, Pearson correlation coefficient, and multiple regression analysis, the results of the study reached the following:

- The most common treatment pattern for mothers was the democratic one.

- The level of emotional balance among kindergarten children was average.

- The results showed a positive, statistically significant correlation at the significance level $(\alpha=0.05)$ between the total score of the emotional balance scale for kindergarten children and the democratic treatment pattern of mothers.

- The results revealed a statistically significant negative correlation at the significance level $(\alpha=0.05)$ between the total score of the emotional balance scale for kindergarten children and the two types of mothers' authoritarian and abusive treatment.

- The regression analysis results revealed that the patterns of mothers' treatment contribute to the emotional balance of kindergarten children by $34.2 \%$.

- The patterns of mothers' treatment contributed in varying proportions to the emotional balance of kindergarten children, the highest of which was the authoritarian pattern, then the neglectful pattern, and finally the democratic pattern.
\end{abstract}

Keywords: patterns of parental treatment (mother's image), emotional balance, kindergarten children

\section{Introduction}

A child is born like a blank page, thrown into the first and most influential institution of social upbringing, which is the family, and many psychologists in general and childhood psychologists, in particular, believe that the family occupies a prominent place in the formation of the child's personality in the first years of his life due to the interaction between parents and children. And the first years of a child's life are considered one of the most important years in his life, in which the psychological, social, and mental characteristics are formed, in addition to the development of his personality and psychological balance later on. This is because of the weakness of the child and its almost total dependence on adults in terms of satisfying his needs, especially the parents, especially the mother, as the nature of the relationship between the child and his parents through the used treatment methods is later reflected in the drawing of the child's personality, to the extent that this relationship includes warmth, acceptance or rejection and deprivation, the child's response to himself and towards others is formed, if the parental treatment takes a positive direction, it will generate a balanced personality in the future and form a positive image of himself and others, while the negative parental treatment between the child and his parent makes him feel the loss of security and emotional contradiction and the formation of a negative image of himself and others (AlGhadani, 2014). 
Therefore, the methods of parental treatment that the child receives and the safety and positivity of the relationship between the child and parenthood is a prerequisite for the psychological and emotional balance of the child and a basis for his later stability (Kazlet, 2007).

The family is the mirror on which culture is reflected. In it, the individual learns and draws from what he sees and hears of values, customs, social trends, and behaviors, and learns right and wrong, rights and duties, and as a general rule, a stable family that satisfies the needs of the child and provides him with care, attention, and affection, and the interactions between its members are positive, is an important factor in achieving happiness and mental health and preventing psychological and behavioral disorders for children, and vice versa. On the other hand, the troubled family is undoubtedly a fertile breeding ground for behavioral and psychological deviations (Abu Aziza, 2009).

The individual's personality grows through the methods of treatment that he receives from his parents. If these methods are full of love, acceptance, and tolerance, they help him build his personality normally, but if it is bad, it negatively affects his emotional balance and psychological state.

The basis of a sound family upbringing is derived from the Holy Qur'an and the Sunnah of His Prophet, which refines morals and purifies souls. The Prophet (peace be upon him) gave us the ideal example in clarifying these methods as he asks parents to be kind to children and treat their mistakes in a spirit of compassion, kindness, and mercy. And parents should know the motivations that led to their mistakes and work to correct them and make their children understand their results, just as the Prophet (peace be upon him) did not impose severity and violence in treating children (Al-Sabawi, 2010). Among the methods of Islamic education are the following: The role model method, where learning by observation and modeling is one of the most important learning methods, especially for children at this stage, where their parents are models for them to follow and imitate. A good example is one of the most prominent means in education, and one of the methods of successful upbringing is for parents to be a role models in front of their children in all their behavior and the method of exhortation. And it is one of the most critical educational means influencing the child's upbringing and preparing him morally, psychologically, and socially. The Noble Qur'an instructs parents to exhort their children in love and kindness and to use the method of discourse that indicates love, compassion, and kindness and taking care of them; also among the methods is the method of intellectual persuasion. Islam has called for reason and sound logical thinking in understanding the facts of things and distinguishing between right and wrong, with argument and proof. Finally, the method of stories, and this method is considered one of the most important methods of modern education, especially in the stage of kindergarten children, because of the psychological impact of stories on children, especially if they are placed in an interesting mold that attracts the child's attention and affects his emotions and conscience (Maqhout, 2014).

Islamic education is considered the most important system through which it is possible to transmit the principles and values contained in Islamic legislation, and the example of Alia has been keen to translate them into practical behavior. It is one of the most important foundations that prepare the individual and build his personality from all aspects, physically, mentally, and socially; based on It is characterized by comprehensiveness, integration, and psychological and emotional balance (Abu Jadu, 2020).

Parental treatment methods are defined as parents' behaviors and methods in normalizing and socializing their children. They may be intentional or unintended, leading to the formation of the children's personality and determining their behavior (Khader, 2012). It is also defined as the means that parents use verbal and non-verbal in their interaction with their parents to socialize (Muhammad \& Muhammad, 2010). Mahrez (2005) defines it as the set of behaviors that fathers and mothers practice in various situations during their upbringing and raising of their children. Ibriem (2011) defines it as how parents provide their children with independence, values, ability to achieve, and self-control. As for Bukatko and Daehler (1992), they explained that the methods of parental treatment have three directions: reporting, which includes explanation and interpretation, and force, and includes cruelty and bullying, and methods of rejection and neglect. The methods of parental treatment practiced by parents with their children during socialization ranged, as mentioned in this study, between the democratic method, which is characterized by giving love, attention, acceptance, focus on dialogue, providing support, psychological security, respecting the child's opinion, relying on persuasion and discussion, and creating an atmosphere of love and mutual respect (Mahrez, 2003). The authoritarian pattern, which is characterized by the use of cruelty and verbal or physical punishment, and the passive pattern, which is characterized by little guidance and supervision of children, leaving the child without any encouragement for the desired behavior and without accountability for the unwanted behavior, as well as leaving the child without any guidance as to what should be done or what should be avoided (Al-Qaisi, 2020).

Among the theories that explain parenting methods: 
- $\quad$ Psychoanalytic Theory: Analytical psychologists, including Freud, consider that the child acquires the ego through his relationship with his social environment, for the higher ego, the child acquires it through the manifestations of authority prevailing in the family, and Freud considered that the interaction between parents and their children is the main element in the formation of their personality in the future when the child moves from one stage to another, he will assume the characteristics of his parents to integrate them into the conscience (AlYamani, 2014).

- Psychosocial development theory: Erikson believes that healthy growth occurs in the social and cultural context of the family, and Erikson identified eight developmental stages and that in each stage, the individual faces a crisis in which the individual is required to modify his behavior to conform to the surrounding environment, and the ways that the individual follows in overcoming these crises are greatly affected by the methods of parental treatment, in addition to other methods (Ben Hammou, 2018).

Self-theory: The owners of this theory, such as Carl Rogers, point to the importance of the methods practiced by parents in the upbringing of their children and their effect on the formation of their personality, where the self is formed through the interaction between the child and his environment, the most important of which is the family environment represented by the parents (Al-Sanani, 2009).

- Cognitive theory: Piaget sees that the child's development is the result of the child's interaction with the surrounding environment, and he supposes that the rich environment provides the child with more experiences that help him to grow and adapt quickly to the environment through which the individual achieves balance, and Piaget looks at the social development of the child through the prevailing relationships with his family, which go hand in hand with his cognitive development (Sabah, 2016).

- The Behavioral Theory: Behavioralists, including Skinner, emphasized the importance of external experience and that the child is born with a readiness that represents the raw material for building his personality through what the individual learns from his parenting first and from other institutions of socialization (Al-Mashi, 2009).

Parental treatment methods vary according to the society in which the child lives, the prevailing culture in the family, and the nature of interactions; the effects of this interaction are reflected on the individual's behavior and personality in general, and the family is one of the main social upbringing institutions that affect its members in all aspects of their lives. Therefore, the family atmosphere and the nature of the prevailing relationships play an important role in an individual's behaviors. Thus, the nature of the relationship between parents and children, in which love and acceptance prevail, is one of the most important factors that protect against psychological problems. On the contrary, parental treatment based on neglect and fluctuation is one of the most dangerous factors in children's behavior (Al-Muhtasib, 2012).

Emotional balance is a manifestation of an individual's mental health, as an emotionally balanced person responds to situations and problems he faces with flexibility and non-extremism. Thus, he is a person characterized by optimism, psychological stability, and freedom to a large extent from feelings of anxiety and psychological loneliness. Emotional balance is necessary for individuals in all age stages, its importance increases for kindergarten children due to the nature and characteristics of the critical stage, and therefore this balance can be considered a characteristic that distinguishes the kindergarten child who interacts with emotional situations without extremism or exaggeration, and can control and control his various emotions, and flexibility in dealing with situations so that he provides an appropriate emotional response (Abbara, Rahal, \& Musa, 2019).

Al-Zogoul et al. (2014) mentioned that emotional balance represents the individual's ability to control his emotions and not be drawn into the influence of external events to become vulnerable to rapid mood swings. Hamdan (2010) defines it as psychological flexibility, which is characterized by moderation towards various emotions and the satisfaction of biological and psychological needs, and considered it the spiritual aspect of personality. Khalifa and Abdullah (2011) consider that emotional balance is a feature that makes the individual react without extremism towards different emotional situations and that emotional imbalance makes the individual present turbulent and rapidly changing emotional responses. As for Agrawa and Kehksha (2015), they see that emotional balance is the process in which the personality constantly seeks to obtain a sense of mental health and that the emotionally balanced individual can postpone the satisfaction of his needs, bear a reasonable amount of frustration and review expectations in the light of circumstances and developments.

Given the importance of emotional balance in being one of mental health indicators, psychological theories have addressed this concept. Freud, the founder of psychoanalytic theory, believed that man is a biological being more than a social being and that the balance of man is a physiological balance that stems from the satisfaction of instincts, so most people, according to Freud, are neurotic to some degree, Freud greatly emphasized the conflict that occurs between personality systems, which is the cause of emotional balance disorder (Revert, 2010). 
Rogers believes in the theory of the self that man is motivated to achieve positive needs and goals because he is a social being with the ability to determine his destiny and control it, and that the individual's emotional imbalance, according to Rogers, is due to his failure to satisfy his needs for positive consideration (self-esteem). At the same time, "Maslow" sees that the individual's emotional imbalance arises due to his failure to satisfy social needs such as love and belonging. The needs of appreciation (Grotevant, 2013) and the behavioral theory sees that personality is the product of learning and that the individual's positive and negative habits can be learned through reinforcement. Abnormal and unbalanced behavior can be learned in the same way. Therefore, emotional balance is achieved through the individual's awareness of all the circumstances that lead to the creation of unbalanced behavior, and the individual who enjoys emotional balance, according to this theory, is characterized by acquiring successful, balanced, and acceptable behavior that helps him to adapt with himself and with others, and to face situations in which he is exposed to stimuli that lead to hesitation and fear of the future (Cooper \& Fornells, 2015).

Existentialists believe that only individuals can choose or make a decision, and individuals who possess a healthy (balanced) personality bear responsibility for their actions and the consequences of their decisions that may be painful, and they can overcome obstacles and environmental conditions and pressures. Existentialists also stress the link between individual freedom and anxiety, where an imbalance precedes the action or the choice process that the individual takes in the face of the future life (Hurlock, 2010).

Many studies have proven that the inconsistency in parental treatment methods is a reason for children to practice abnormal behavior. One of the causes of emotional imbalance is the study (Kumar, 2013) which indicated a positive relationship between parenting methods, represented by neglect, rejection, aggressive behavior, anxiety, depression, and emotional imbalance in children. The study (Abdin, 2010) indicated that parental treatment methods characterized by violence, cruelty, and discrimination would enhance the emergence of withdrawn and abnormal personalities in children and poor emotional and psychological compatibility. Costa et al. (2015) also showed a relationship between the pattern of parental treatment based on control and cruelty and internal problems that the child is exposed to throughout his life. The results of many studies also showed that the individuals who are most able to control their emotions are the ablest to control their behavior, and they are more able to feel confident during their interaction with the surrounding environment, especially the mother, which gives him the freedom to interact with others and to play his roles efficiently and positively (Serebryakova, 2016). Also, most studies prove that children who are given a kind of parental warmth, acceptance, and affection have a high degree of compatibility and psychological and emotional balance. At the same time, children who witness cruelty, neglect, and discrimination methods have a high degree of psychological imbalance (Al-Tamawi, 2020).

\subsection{Study Problem and Its Questions}

Many psychologists such as Freud, Erikson, and Piaget emphasize the importance of childhood in an individual's life as it is a stage of formation of his behavior and the growth of his readiness and abilities and determining his course in all aspects, at this stage, parents represent the basis for the child's psychological and social stability and a source of his sense of security and self-confidence (Yasmina \& Zahia, 2018). And based on the nature of the relationship that arises between the child and his parents, especially the mother at this stage, and the positive or negative impact on the child's personality and emotional balance, the origins of social upbringing require the presence of the mother and her active role in the socialization process, as the mother is a support for the father, as he cannot alone, especially at this stage, carry out the process of socialization to the fullest, because the mother spends a long time with the child and is considered a source of emotional warmth, a source of satisfaction for his needs, and a basis for his normal growth in all physical, psychological and emotional aspects (Abra'im, 2011).

The methods of parental treatment vary according to the economic and social environment to which the family belongs, between the positive method represented by democracy and encouragement, and the negative method represented by excessive protection and rejection, and both methods affect, positively or negatively, the child's personality, psychological and social balance, and self-esteem (Belkheir, 2020). Where the problem of the study emerged in clarifying the degree of contribution of mothers' treatment patterns to the emotional balance of kindergarten children, considering that most of the psychological and behavioral problems that appear in children are often due to the conflict that arises in children from the emotional contradiction in the child's relationship with his parents, as many studies have shown such as the study of Al-Shboul (2010), Mustafa (2010), and Al-Khatib et al. (n.d.). Parents' use of wrong methods in raising their children may lead to devastating psychological and behavioral effects on the child's personality, such as deviation, introversion, anxiety, lying, theft, aggression, and psychological imbalance (Al-Ghadani, 2014).

Given the interest of researchers in the field of childhood and the researchers' failure to notice any Arab or local predictive study - according to the researchers' knowledge - that dealt with the degree of contribution of mothers' 
treatment patterns to the emotional balance of kindergarten children in particular, and that most of the studies in the field of childhood dealt with methods of parental treatment and its relationship to emotional balance was on verbally disturbed children, such as the study of Al-Adani (2014) or on older age groups, such as the study of AlKhouribi (2002) and Al-Qaisi (2020). Therefore, in light of the foregoing, this study came to try to reveal the degree of contribution of mothers' treatment patterns to the emotional balance of kindergarten children by answering the following questions:

1) What are the most common maternal treatment patterns?

2) What is the level of emotional balance for kindergarten children?

3) Is there a statistically significant relationship between mothers' treatment patterns and the emotional balance of kindergarten children?

4) What is the contribution of mothers' treatment patterns to the emotional balance of kindergarten children?

\subsection{Objectives of the Study}

- Uncover the most common mothers' treatment patterns.

- $\quad$ Detect the level of emotional balance in kindergarten children.

- Detect a statistically significant relationship between mothers' treatment patterns and emotional balance among kindergarten children.

- Detecting the extent to which mothers' treatment patterns contribute to the emotional balance of kindergarten children.

\subsection{The Importance of the Study}

The importance of the current study shows that it deals with an important stage, which is the kindergarten stage, and what children may be exposed to at this stage of variation in the methods of parental treatment (the image of the mother) and its impact on their emotional balance, and the importance of the study appears in the following:

- The study contributes to giving a clear picture of the most common patterns of parental treatment (the image of the mother).

- Detect the level of emotional balance in kindergarten.

- $\quad$ Shedd light on emotional balance as a concept that did not get enough luck in Arabic studies, especially at the kindergarten stage

- Inform the family and those in charge of raising the child about the patterns of mothers' treatment that contribute to the child's emotional balance.

- It specifically benefits those responsible for raising the child and the mother by laying down new foundations and methods for dealing with the child to achieve psychological balance.

- The study benefits researchers and those in charge of child-rearing to benefit from the current study tools.

\subsection{The Limits of the Study}

The study was applied within the following limits:

- Objective limits: It is the detection of the degree of contribution of the treatment patterns of mothers to the emotional balance of kindergarten children.

- Human limits: The study was applied to a sample of private kindergarten children in the Naour District Education Directorate in the Jordanian capital Amman governorate.

- Spatial limits: The study was applied in private kindergartens affiliated to the Naour District Directorate in the Capital Governorate of Amman in Jordan.

- Temporal limits: The current study was applied at the beginning of the second semester of the academic year (2020-2021 AD), when education was prevalent at the beginning of the semester.

\subsection{Limitations of the Study}

The generalization of the results of this study is determined in the light of the following:

- What the study's scales enjoy is “the scale of parental treatment patterns (mother's image), and the emotional balance scale consists of psychometric properties represented by honesty and stability.

- The integrity of the application procedures and the objectivity of the responses of the study sample members 
to the questionnaire.

\subsection{Terminological and Procedural Definitions}

This study includes the following terminological and procedural definitions:

- $\quad$ Patterns of parental treatment (Mother picture): It is the set of behaviors practiced by parents (Mother picture) with their children in various situations during their upbringing (Mahrez, 2003). It is procedurally defined by the degree that the child obtains on the scale of mothers' treatment patterns used in this study. The researchers define it in the study as the processes that mothers practice in raising their children, directing them, and controlling their behavior to impart community habits and values as they see fit.

- Emotional balance: It is the personality trait that includes the ability of the owner to regulate his emotions, control them, control his behavior, adapt to difficulties, and identify different life situations (Losel \& Bender, 2011). It is procedurally defined by the degree that the child obtains on the emotional balance scale used in this study.

- Kindergarten children: They are children whose ages range between 3-4 years and enroll in one of the private or government kindergartens and provide them with various educational programs that help them grow from all sides (Abu Saleh, 2017).

\section{Previous Studies}

\subsection{Studies Related to Patterns of Parental Treatment}

Al-Badrin (2012) conducted a study aimed at knowing the extent of the joint contribution of parenting methods, identity methods, and academic adaptation to the academic competence of the Hashemite University students. The study sample consisted of 140 male and female students. The results of the study showed the existence of a statistically significant joint contribution of parenting patterns to self-efficacy and academics, and the results showed a significant predictive ability of democratic parenting patterns, informational identity patterns, identity commitment patterns, and academic adaptation to academic self-efficacy.

Maghout (2014) conducted a study to reveal the methods of parental treatment among outstanding adolescents in the intermediate education certificate at Al-Quba Al-Jadida High School for Mathematics. The study sample consisted of 106 male and female students in the first year of secondary school; the descriptive survey approach was used. The results showed that the most important methods of parental treatment of the father's image and the mother's image that encourages academic excellence as children perceive it was the normal methods represented in democracy. On the other hand, improper treatment methods limit academic excellence. Furthermore, there are no statistically significant differences between fathers and mothers in the use of normal and inappropriate treatment methods, which means that children are aware of these methods practiced by parents, whether normal or not. In the same way, there are no statistically significant differences between males and females in the children's perception of the methods of treatment (father) and (mother) in positive and negative methods.

Al-Sharaa and Al-Momani (2019) conducted a study aimed at uncovering the prevailing pattern of socialization in the Jordanian family and its relationship to the sex of the child, the family's income level, the number of its members, and the educational level of the parents; the study sample consisted of 144 male and female students in the College of Education at Yarmouk University. The study results showed that the most common patterns of social upbringing are the democratic pattern, followed by the overprotective and authoritarian pattern, followed by the discriminatory pattern in the last order. The results also showed that there were statistically significant differences in the neglected pattern according to the variables of sex and mother's education level in favor of males and in favor of illiteracy, and in the authoritarian pattern with different levels of income in favor of middle income, and with the difference in the number of family members in favor of large families, and in the pattern of excess protection according to the level of education of the father in favor of secondary education, and in the democratic pattern according to the level of mother's education in favor of secondary education.

The study (Asep, Tukimin, \& Fitria, 2021) aimed to determine the relationship between common parental treatment patterns and the emotional dynamics of the parents, and the social and emotional interaction of mentally disabled children. This research used the quantitative method, where the random sample consisted of 96 children with special needs. The results of this study showed that the common parental treatment pattern is the democratic pattern, where the percentage of those who apply democratic education was $79.2 \%$, then the authoritarian pattern came in second place with a percentage of $13.5 \%$, then the passive pattern with a percentage of $7.2 \%$. Where the random sample consisted of 96 children with special needs. The results of this study showed that the common parental treatment pattern is the democratic pattern, where the percentage of those who apply democratic education was $79.2 \%$, then the authoritarian pattern came in second place with a percentage of $13.5 \%$, then the passive pattern 
with a percentage of $7.2 \%$. The results also revealed a positive, statistically significant relationship between democratic parenting patterns and social and emotional interaction of mentally disabled children. There is a positive relationship between the emotional dynamics of parents and the social interactions of mentally disabled children.

\subsection{Studies Related to Emotional Balance}

Yagnik (2013) conducted a current study to compare the level of emotional equilibrium and family adaptation for children of working and non-working women. The sample consisted of 300 boys and girls from four randomly selected schools in Ahmedabad from the state of Gujarat in India. Among them were 150 children of a working woman and 150 children of a non-working woman. The Emotional Balance and Family Adjustment Questionnaire was prepared. The results showed that there were statistically significant differences between the average scores of children of working and non-working mothers on the scales of emotional balance and psychological adjustment. In addition, the results showed medium levels of emotional balance among non-working mothers and high levels of emotional balance among working mothers, and the differences were in favor of the children of non-working mothers, where the emotional balance and psychological adjustment of working children were more than the children of non-working mothers.

Kumar (2013) conducted a study in India that aimed to reveal the level of emotional balance and its relationship to students' social and economic levels studying in public and private secondary schools. The study sample consisted of 100 male and female students who were chosen by random method; the results showed that there were no statistically significant differences in the level of emotional balance among students who study in public and private schools, and there were differences in the general average of the social status of the emotional balance that they are characterized by, and the economic balance of the students accordingly. In addition, the results showed that the level of emotional balance among the study sample members was average.

Attia (2016) conducted a study aimed at revealing emotional balance and its relationship to self-control among Yarmouk University students. The sample of the study consisted of 749 male and female students. Using the descriptive survey method, the results showed that the level of emotional balance among Yarmouk University students was moderate, it also showed that there were statistically significant differences in the level of emotional balance due to the gender variable in favor of males. And there were no statistically significant differences in the level of emotional balance due to the variables of academic level and specialization. The results also showed that the level of self-control among students was average, and there was a significant correlation between emotional balance and the level of self-control.

Al-Tamawy (2017) conducted a study aimed at revealing the relationship between identity disorder and emotional balance according to the different methods of parental treatment among adolescents from secondary school students. The study sample consisted of 200 male and female adolescents from government schools in Sohag; the results also revealed a positive relationship between identity disorder and negative treatment methods, as well as a negative relationship between emotional balance and negative parental treatment methods, and a negative relationship between identity disorder and emotional balance in adolescents. The results also revealed a positive relationship between identity disorder and negative treatment methods, a negative relationship between emotional balance and negative parental treatment methods, and a negative relationship between identity disorder and emotional balance in adolescents. Maciel et al. (2018) conducted a study to reveal the relationship of balance in positive emotional expression in children, high level of social competence, and lower maladjustment in childhood. The study sample consisted of 301 kindergarten children. The results of the research showed that the balance in positive emotional expression during lunch/break compared to positive expression in the classroom was associated with a decrease in teacher-student conflict, external behaviors, and depressive symptoms, and the balance in general positive emotional expression predicted fewer outward behaviors as well as reduced symptoms of depression and anxiety. The results point to the importance of assessing the ratio of positive emotional expression observed in context as a potential indicator of maladaptive risk in children and the need for children to adapt their emotions to different contexts. Hamad (2019) conducted a study aimed at measuring the emotional balance of university students and knowing the significance of the differences in emotional balance among a sample of Baghdad University students according to the gender variable. The study adopted the 2007 Khalidi scale in emotional balance. The study concluded that the level of emotional balance among university students is high, and there were no significant differences in emotional balance among university students attributed to the gender variable.

The study of Robert and William (2017) aimed to identify the ability of kindergarten teachers in Canada to discover the psychological problems of kindergarten children and find solutions to them. The sample consisted of 160 
children, and the descriptive survey method was used to achieve the objectives of the study. A questionnaire consisting of 54 items was prepared as a study tool. A comparison was made between teachers, parents, psychologists and social specialists in which one is better and more capable of discovering the problems of kindergarten children. The research concluded that the teachers are the most able to discover psychological and behavioral problems for children in the kindergarten stage, and then refer it to specialists, as they are more in contact with and observe children during various activities, during free play, and through many situations that occur during the many hours spent in kindergarten.

Mousa's study (2019) aimed to measure the effectiveness of the proposed training program in developing some soft skills (body language skill - time management skills) for kindergarten teachers in Assiut Governorate in Egypt to improve communication with children and consider their requirements. The research sample consisted of a random sample of kindergarten teachers numbering 40 parameters, divided into two groups, experimental and control, each group numbered 20 teachers. Then the two research tools - the observation card, and the achievement test - were applied to them previously. The training program was implemented according to the schedule set in advance, and after the research experiment was completed, the two research tools - the observation card, and the achievement test - were applied afterward on the kindergarten teachers (the research sample), then statistical treatment was carried out. The results showed that there were statistically significant differences at the significance level 05.0 in the soft skills level of kindergarten teachers in favor of the experimental group, which indicates the effectiveness of the training program in developing some soft skills (body language skill-time management skill) for kindergarten teachers to improve communication with children and take into account their requirements.

\subsection{Studies Related to Patterns of Parental Treatment and Emotional Balance and Its Fields}

Al-Khouribi (2002) conducted a study to identify the methods of parental treatment as perceived by children of both sexes and their relationship to emotional balance in the age group 14-17 years. The study sample consisted of 505 male and female students from the secondary stage in Cairo Governorate. The study results concluded that there is a positive correlation between the methods of proper parental treatment represented by democracy and the level of emotional balance among children of both genders.

Ibriem (2011) conducted a study that aimed to reveal the relationship between the father's treatment methods as perceived by his children and their relationship to a feeling of psychological security among a sample of secondary school students in the city of Tebessa. The study sample consisted of 186 male and female students, and using the correlative approach, the results of the study concluded that there is a negative correlation between the children's perception of the father's treatment methods (discrimination, control and control, volatility) and their sense of psychological security. There is a positive correlation between the children's perception of the proper treatment method and their sense of psychological security.

Amara and Bouisheh (2013) conducted a study to uncover the relationship between democratic family dialogue and emotional equilibrium among adolescents. The study sample consisted of 197 male and female students in the Algerian city of Tikrit; the results of the study showed a weak relationship between democratic family dialogue and emotional balance among adolescents, as well as the presence of significant differences between the democratic family dialogue and emotional balance among adolescents according to the gender variable in favor of females, and the presence of significant differences between the democratic family dialogue and emotional balance among adolescents according to the variable number of family members in favor of five or more individuals.

Al-Ghadani (2014) conducted a study that revealed the methods of parental treatment as perceived by the children and their relationship to emotional balance among the verbally disturbed in the Governorate of Muscat. Although the study sample amounted to 55 children, the results of the study indicated that there is a negative relationship between the unorthodox treatment methods as perceived by the children and emotional balance and the absence of statistically significant differences in the methods of parental treatment as perceived by the children due to the economic and social level of the family.

Al-Rawahiya (2016) conducted a study to reveal the methods of parental treatment as perceived by the twelfthgrade students and their relationship to psychological adjustment in the Al Dakhiliyah Governorate. The researcher used the descriptive approach, and the study sample was 100 students. The results of the study showed that the most common parental treatment method is the democratic method, and the results showed that the field of family adjustment is the most common; the results also showed a positive correlation between the democratic treatment pattern and psychological adjustment and a negative relationship between the abnormal method and psychological adjustment.

Al-Fraihat and Al-Muqabala (2017) conducted a study to identify the predictive ability of the family communication environment, social, emotional, and academic self-efficacy, and cognitive flexibility among tenth- 
grade students in Ajloun Governorate; the study sample consisted of 400 male and female students. The results showed that the student's cognitive flexibility level was medium, and social, emotional, and academic self-efficacy was high. The results also indicated that the most prevalent form of family communication was the dialogue pattern, and there were significant differences in social, emotional, and academic self-efficacy due to the gender variable in favor of females. The results also showed a significant contribution degree for each social, emotional, and academic self-efficacy and dialogue patterns to predict cognitive flexibility.

Shurrab (2019) conducted a study aimed at examining the ability of both family climate and psychological security to predict electronic violence and the difference in electronic violence according to different variables: social gender, family size, and physical arrangement, among the age group 14-16 years, the results resulted in: There is a significant positive relationship between family climate and psychological security, and a significant negative relationship between family climate and electronic violence on the one hand, and psychological security on the other hand, as well as the ability of both family climate and electronic security to predictive psychological security, it also found differences in electronic violence in favor of males, while it did not show any differences in electronic violence, according to the variables of family size and birth order.

Al-Tamawi's (2020) study aimed to uncover the relationship between parental treatment methods and psychological compatibility among adolescents, as the study sample consisted of 100 students aged 15-18 years from Al-Shaheed Al-Husseini Secondary School (Tama). The study results concluded that there is a negative relationship between negative parental treatment methods and psychological compatibility and the difference in the use of parental treatment methods by parents according to the gender of the children.

The study of Al-Qaisi (2020) aimed to identify the level of emotional balance and its relationship to the methods of parental upbringing among a sample of students of the Faculty of Educational Sciences at the University of Islamic Sciences. The study sample consisted of 184 male and female students. The results of the study showed a low level of emotional balance among students, and a negative relationship between parenting patterns (chaotic and authoritarian) and emotional balance among the sample members, as well as the existence of a positive relationship between the method of democratic upbringing and emotional balance, as well as a statistically significant effect of emotional balance according to the gender variable in favor of males, and the family size variable in favor of large families.

The study (Yildirim \& Ayas, 2020) aimed to reveal the relationship between psychological well-being, parenting pattern (parenting), and smartphone addiction among school students in Kocaeli province in Turkey. The sample consisted of 671 male and female students in the secondary stage, who are studying in six different secondary schools, who were randomly selected; a smartphone addiction scale, psychological well-being scale, and parenting pattern scale were applied to them. The study results revealed that there were no statistically significant differences in the levels of smartphone addiction according to the gender variable and parental income level, and there is a negative and statistically significant relationship between academic achievement and smartphone addiction. The results also revealed a positive correlation between the authoritarian parenting pattern with smartphone addiction. The regression analysis results indicated that the authoritarian parenting pattern predicts smartphone addiction by children, and the results of the regression analysis showed that psychological well-being was the most important predictor of smartphone addiction.

\section{Commenting on previous studies}

In light of the review of previous studies that dealt with patterns of parental treatment and emotional balance, we note that some studies dealt with each variable independently, and among the studies that dealt with patterns of parental treatment and on various samples, primary, secondary and university stage, are the Makhout study (2014), and the Shari'a and Momani study (2019). In addition, some studies examined emotional balance independently in Arab and foreign environments and on various samples, primary and secondary, university stage and on mothers, or with other variables such as the study (Yagnik, 2013; Kumar \& Al-Tamawi, 2017; Hamad, 2019). As for the studies that dealt with the methods of parental treatment and its relationship to emotional balance, they were on older ages, such as high school and university students, and in different environments, such as the study of AlKhouribi (2002), Ibraim (2011), Amara and Bouisha (2013), Al-Rawahieh (2016), Al-Tamawi (2020) and AlQaisi (2020) and Yildirim and Ayas (2020), and some of them are on verbally striking children, such as the study of Al-Ghadani (2014).

Therefore, the current study was distinguished from previous studies in that it is the only study among the previous studies in this field that followed the predictive methodology of these two variables in knowing the degree of contribution of mothers' treatment patterns to the emotional balance of kindergarten children, and it was one of the single studies of these two variables conducted on kindergarten children, in the Jordanian and Arab 
environment. And the researchers benefited from previous studies in reviewing the theoretical frameworks related to patterns of parental treatment and psychological balance, developing the two measures of the study, justifying conducting the current study, and discussing the results in the light of comparing its results with the results of that study.

\section{Methodology}

The descriptive correlative approach was followed to determine the degree of contribution of mothers' treatment patterns to the emotional balance of kindergarten children due to its relevance to the study's nature and its questions.

\subsection{The Study Population}

The study population included all private kindergarten children from 5-6 years who are registered in the Directorate of Education in Naour District in the Capital Governorate Amman for the academic year 2020-2021, and their number is 649 .

\subsection{The Study Sample}

The study sample consisted of 195 children from the age of 5-6 years who were randomly selected from the private kindergartens of the Naour Brigade in the Amman Governorate, representing a percentage of $30 \%$, and the mothers' treatment patterns scale and the psychological balance scale were distributed to the female teachers, where the teacher reads the items of each of the scales to the children.

\subsection{The Study Tools}

Two tools were built to achieve the objectives of the current study, namely: the maternal treatment pattern scale and the psychological balance scale, and they are as follows:

\subsubsection{A Scale of Mothers' Treatment Patterns}

After reviewing the theoretical literature, previous studies, educational research, and the standards used, such as Abu Ishaq (2002), Mahrez (2003), Zughayer (2007), Hassan (2008), Younis (2015), Abdel Maqsoud (2015), A scale of mothers' treatment patterns were built, where the scale in its final form included 30 items, distributed over three areas: The democratic and its item s (1-10), the authoritarian and its item s (11-20), and Al-Tasibi and its item s (21-30).

\subsubsection{Indicators of Construction Validity, a Scale of Mothers' Treatment Patterns}

The construction validity indicators were used to measure mothers' treatment patterns by applying them to an exploratory sample of 25 boys and girls from kindergartens in the Naour District and outside its sample, then the correlation coefficients were extracted between the item and the dimension to which it belongs, where the indicators of construction validity for the democratic pattern ranged between $0.419-0.872$, for the authoritarian pattern between 0.476-0.901, and for the passive pattern between 0.522-0.845, All of these indicators are statistically significant at the significance level $(\alpha=0.05)$, and Table 1 illustrates this. 
Table 1. Correlation coefficients - indicators of construct validity-between the item s of the Parental Treatment Methods Scale (mother's picture) and the dimension to which the item belongs

\begin{tabular}{lllllllll}
\hline \multicolumn{2}{l}{ Democratic pattern } & \multicolumn{3}{c}{ Authoritarian pattern } & \multicolumn{3}{l}{ Stippling pattern } \\
\hline Item & Correlation & Significance & Item & Correlation & Significance & Item & Correlation & Significance \\
\hline 1 & $.838^{* *}$ & .000 & 11 & $.619^{* *}$ & .001 & 21 & $.746^{* *}$ & .000 \\
2 & $.481^{*}$ & .015 & 12 & $.901^{* *}$ & .000 & 22 & $.528^{* *}$ & .007 \\
3 & $.872^{* *}$ & .000 & 13 & $.748^{* *}$ & .000 & 23 & $.522^{* *}$ & .007 \\
4 & $.565^{* *}$ & .003 & 14 & $.510^{* *}$ & .009 & 24 & $.845^{* *}$ & .000 \\
5 & $.460^{*}$ & .021 & 15 & $.682^{* *}$ & .000 & 25 & $.703^{* *}$ & .000 \\
6 & $.789^{* *}$ & .000 & 16 & $.476^{*}$ & .016 & 26 & $.717^{* *}$ & .000 \\
7 & $.652^{* *}$ & .000 & 17 & $.709^{* *}$ & .000 & 27 & $.553^{* *}$ & .004 \\
8 & $.419^{*}$ & .037 & 18 & $.605^{* *}$ & .001 & 28 & $.541^{* *}$ & .005 \\
9 & $.644^{* *}$ & .000 & 19 & $.574^{* *}$ & .003 & 29 & $.643^{* *}$ & .001 \\
10 & $.751^{* *}$ & .000 & 20 & $.518^{* *}$ & .008 & 30 & $.635^{* *}$ & .001 \\
\hline
\end{tabular}

\subsubsection{Reliability in Maternal Treatment Patterns}

An exploratory sample consisted of 25 boys and girls from kindergartens in the Naour district and outside the study sample, and according to Cronbach's Alpha reliability coefficient on the first measurement, where the reliability coefficients ranged between $0.800-0.834$, also, the application was re-applied a second time on the same sample after two weeks, and according to the reliability of the repetition (Test-Retest) through the Pearson correlation coefficient between the first and second applications, where the reliability coefficients of repetition ranged between 0.899-0.940, which are high coefficients indicating that the scale has a high and acceptable reliability coefficient, and Table 2 shows that.

Table 2. Cronbach's alpha reliability coefficient for the dimensions and repeatability of the mother's treatment pattern scale

\begin{tabular}{lll}
\hline Pattern & Cronbach's Alpha reliability Coefficient & Repetition constancy coefficient \\
\hline Democratic pattern & 813.0 & 913.0 \\
authoritarian pattern & 0.834 & 0.940 \\
Stippling pattern & 800.0 & 899.0 \\
\hline
\end{tabular}

\subsubsection{Psychological Balance Scale}

After reviewing the theoretical literature, previous studies, educational research, and the standards used, such as Rayan (2006), Hamdan (2010), Abu Zaitoun (2010), Sammour (2012), Abu Mustafa (2015), and Al Khamisa (2018). Where the emotional balance scale was built, and the scale in its final form included 23 items that measure the total degree of emotional balance in children.

\subsubsection{Indicators of the Construct Validity of the Emotional Balance Scale}

The construction validity indicators were used to measure the emotional balance by applying it to a pilot sample of 25 boys and girls from kindergarten in the Naour District and outside its sample, then the correlation coefficients between the item and the total score were extracted. Where the construction validity indicators of the democratic pattern ranged between $0.419-0.872$, and all of these indicators are statistically significant at the significance level $(\alpha=0.05)$, Table 3 shows this.

Table 3. Correlation coefficients - construction validity indicators-between the items of the emotional balance scale and the total score to which the item belongs

\begin{tabular}{lllllllll}
\hline Item & Correlation & Significance & Item & Correlation & Significance & Item & Correlation & Significance \\
\hline 1 & $.749^{* *}$ & .000 & 9 & $.529^{* *}$ & .007 & 17 & $.482^{*}$ & .015 \\
2 & $.484^{*}$ & .014 & 10 & $.517^{* *}$ & .008 & 18 & $.721^{* *}$ & .000 \\
3 & $.681^{* *}$ & .000 & 11 & $.734^{* *}$ & .000 & 19 & $.594^{* *}$ & .002 \\
4 & $.570^{* *}$ & .003 & 12 & $.517^{* *}$ & .008 & 20 & $.509 * *$ & .009 \\
5 & $.605^{* *}$ & .000 & 13 & $.655^{* *}$ & .000 & 21 & $.528^{* *}$ & .007 \\
6 & $.574^{* *}$ & .000 & 14 & $.628^{* *}$ & .000 & 22 & $.616^{* *}$ & .001 \\
7 & $.553^{* *}$ & .000 & 15 & $.704^{* *}$ & .000 & 23 & $.624^{* *}$ & .000 \\
8 & $.608^{* *}$ & .000 & 16 & $.585^{* *}$ & .002 & & & \\
\hline
\end{tabular}




\subsubsection{Reliability of Emotional Balance Scale}

An exploratory sample was selected consisting of 25 boys and girls from kindergartens in the Naour District. Outside the study sample, according to Cronbach's Alpha on the first measurement, where the reliability coefficient was 0.828 , it was also re-applied a second time on the same sample after two weeks. The reliability of repetition was calculated (Test-Retest) through the Pearson correlation coefficient between the first and second applications, where the coefficients of repetition reliability were 0.883 . These are high coefficients that indicate that the scale has a high and acceptable reliability coefficient.

\subsection{Correction of the Two Study Scales (Maternal Treatment Patterns Scale/Emotional Balance Scale)}

The answer to the item s of the scale is of the type of triple scale (always, sometimes, never), and the scale was corrected by giving the previous scale the numbers $(3,2,1)$ and to determine the levels of arithmetic averages the following equation was used:

Category length $=$ upper - lower $($ for gradation $)=(3-1)=2 / 3=0.66$

The number of levels assumed 3

- Averages ranging from (1-1.67), low.

- $\quad$ Averages are ranging from (1.68-2.34), average.

- $\quad$ Averages are ranging from (2.35-3), high.

\subsection{Study Procedures}

To complete the study, the researchers performed the following procedures:

- $\quad$ First, review the theoretical literature and previous studies related to parenting methods and psychological balance.

- Determine the population and sample of the study from the children of private kindergartens affiliated to the Naour Brigade in Amman Governorate.

- $\quad$ Prepare the study tools and ensure their validity and reliability.

- Apply the tools to the study sample through the parameters and collect papers for that.

- $\quad$ Dump the data, process it statistically, and draw conclusions.

- Answer the study questions according to its objectives, discuss them and make recommendations.

\subsection{The Study Variables}

Maternal treatment patterns and emotional balance.

\subsection{Statistical Processing}

The following was used:

- $\quad$ Arithmetic averages and standard deviations to answer the first two questions

- Pearson's correlation coefficient to answer the third question

- Multiple regression analysis to answer the fourth question

\section{The Results of the Study}

The results of the study were presented and discussed, and what was consistent or different with the results of previous studies was determined according to the order of its questions, as follows:

\section{Results and discussion of the first question: What are the most common patterns of treatment for mothers?}

To answer this question, the arithmetic averages and standard deviations of the most common mothers' behavior patterns were calculated, and Table 4 illustrates this. 
Table 4. Arithmetic means and standard deviations of the most common maternal treatment patterns

\begin{tabular}{lllllllll}
\hline Rank & $\begin{array}{l}\text { Dimension } \\
\text { No. }\end{array}$ & Dimensions & $\begin{array}{l}\text { Total sample } \\
\text { number }\end{array}$ & $\begin{array}{l}\text { lowest } \\
\text { average }\end{array}$ & $\begin{array}{l}\text { Highest } \\
\text { average }\end{array}$ & $\begin{array}{l}\text { Arithmetic } \\
\text { average }\end{array}$ & $\begin{array}{l}\text { Standard } \\
\text { deviation }\end{array}$ & level \\
\hline 1. & 1 & $\begin{array}{l}\text { Democratic } \\
\text { pattern }\end{array}$ & 195 & 2 & 3 & 2.51 & .229 & High \\
2. & 2 & $\begin{array}{l}\text { authoritarian } \\
\text { pattern } \\
\text { Stippling } \\
\text { pattern }\end{array}$ & & 1 & 2 & 1.82 & .295 & Average \\
3. & 3 & 1 & 2 & 1.40 & .191 & Low \\
\hline
\end{tabular}

Note. Categories: (low) 1-1.67/ (average) 1.68-2.35/ (high) 2.36-3.

It appears from the results of Table 6 that the most common treatment patterns for mothers were in the democratic pattern, where its arithmetic average was 2.51 , with a standard deviation 0.229 . Its level was high, then came the authoritarian pattern in second place, where its arithmetic average was 1.82 , with a standard deviation of 0.295 , whose level was mean, while the least common treatment pattern of mothers was the sedative pattern, where its average was 1.40 , with a standard deviation 0.191 , and its level was low. The researchers explain this result to mothers' awareness of the importance of the democratic pattern in upbringing based on acceptance, tolerance, and dialogue, especially with children of this stage, as they need sympathy, acceptance, direction, and containment, and the authoritarian pattern came in the second place. The researchers attribute this to the keenness of some mothers for their children at this critical stage and the necessity of diligent follow-up for them for fear of making mistakes. The neglectful pattern came in the last place because mothers did not believe in the feasibility of this pattern of upbringing with children. After all, neglecting children and not following them up at this critical age would expose them to danger and deviation.

This result agrees with the study Asep, Tukimin and Fitria (2021) and the study of Blanket (2014). The most common pattern of parental treatment is the democratic one, and this result agrees with the study of Al-Fraihat and Al-Muqabala (2017), whose results revealed that the most prevalent form of family communication was the dialogue pattern. This result completely agreed with the study of Al-Shara'a and Al-Momani (2019) that the most common patterns of socialization are the democratic pattern followed by the authoritarian pattern and the overprotection following the passive pattern.

The results of the second question and its discussion: What is the level of emotional balance among kindergarten children?

To answer this question, the arithmetic averages and standard deviations of the level of emotional balance among kindergarten children were calculated, and Table 5 illustrates this. 
Table 5. Arithmetic averages and standard deviations of the items of the emotional balance scale for kindergarten children arranged in descending order according to the arithmetic averages

\begin{tabular}{|c|c|c|c|c|c|}
\hline Rank & $\begin{array}{l}\text { Item } \\
\text { No. } \\
\end{array}$ & item s & $\begin{array}{l}\text { Arithmetic } \\
\text { average }\end{array}$ & $\begin{array}{l}\text { standard } \\
\text { deviation }\end{array}$ & level \\
\hline 1. & 12 & I return the offense & 2.75 & .432 & High \\
\hline 2. & 10 & I apologize when I'm wrong & 2.68 & .667 & High \\
\hline 3. & 20 & I express what I want easily & 2.65 & .595 & High \\
\hline 4. & 21 & I feel successful in all my works & 2.55 & .585 & High \\
\hline 5. & 11 & I feel loved by my colleagues & 2.53 & .683 & High \\
\hline 6. & 17 & I easily make new friends & 2.49 & .815 & High \\
\hline 7. & 16 & I hesitate when making any decision & 2.48 & .821 & High \\
\hline 8. & 1 & I act quickly and for no reason & 2.46 & .585 & High \\
\hline 9. & 18 & I take the initiative to resolve the quarrel between my friends & 2.45 & .862 & High \\
\hline 10. & 13 & I deal quietly & 2.43 & .496 & High \\
\hline 11. & 23 & I spend most of my moments happy & 2.40 & .796 & High \\
\hline 12. & 22 & I begin to reconcile with those who oppose me & 2.37 & .872 & High \\
\hline 13. & 14 & I quickly adapt to my new peers & 2.25 & .800 & Average \\
\hline 14. & 3 & I regret my actions when I get angry & 2.09 & .765 & Average \\
\hline 15. & 4 & I suppose my control over others & 2.07 & .756 & Average \\
\hline 16. & 6 & I find I'm nervous & 2.07 & .894 & Average \\
\hline 17. & 9 & I fight with my colleagues most of the time & 2.02 & .696 & Average \\
\hline 18. & 5 & My room at home is very tidy & 2.00 & .696 & Average \\
\hline 19. & 8 & I worry for no reason & 1.91 & .785 & Average \\
\hline 20. & 7 & I get angry when someone blames me & 1.73 & .683 & Average \\
\hline 21. & 15 & I share with my colleagues their occasions & 1.64 & .722 & Low \\
\hline 22. & 2 & I adjust my emotions in different situations & 1.63 & .664 & Low \\
\hline 23. & 19 & I feel shy when I talk to others & 1.31 & .465 & Low \\
\hline \multicolumn{3}{|c|}{ The total degree of emotional equilibrium } & 2.22 & .258 & Average \\
\hline
\end{tabular}

Note. Categories: (low) 1-1.67/ (average) 1.68-2.35/ (high) 2.36-3.

It appears from Table 5 that the level of emotional balance among kindergarten children was average, as the arithmetic means of the total score was 2.22 with a standard deviation of 0.258 , and the arithmetic averages of the item $\mathrm{s}$ ranged between 1.31-2.75. The levels of the item $\mathrm{s}$ ranged between low, medium, and high, and item 12 came as follows: "I return the abuse" came in the first rank with the highest arithmetic average of 2.75 , standard deviation 432. and at a high level of appreciation, while item 7 came as follows: "I feel shy when I talk to others" ranked last, with an arithmetic average of 1.31 and with a standard deviation of 895 . and with a low rating level. The researchers explain this result in that the level of emotional balance among children was moderate in that the children at this stage did not sufficiently learn to regulate and control their emotions as they come with experience and the interaction of children with the surrounding environment. Also, children's emotions at this age control them, and they do not realize the consequences of matters greatly, so the level of emotional balance in children is average. This result agreed with the study of Al- Kumar (2013) and the study of Al-Rabee and Attia (2016), whose results showed that the level of emotional balance was moderate and differed from the study of Hamad (2019), whose results showed that the level of emotional balance among university students was high. It partly differed from the study of Al-Fraihat and Al Muqabala (2017) that the level of students' social, emotional, and academic self-efficacy was high.

The results of the third question and its discussion: Is there a statistically significant relationship between the treatment patterns of mothers and the emotional balance of kindergarten children?

To answer this question, the correlation between mothers' treatment patterns and the emotional balance of kindergarten children was calculated, and Table 6 shows the correlation coefficient values. 
Table 6. Pearson's correlation coefficient between mothers' treatment patterns and the emotional balance of kindergarten children

\begin{tabular}{lllll}
\hline \multirow{2}{*}{ Scale } & correlation & \multicolumn{4}{l}{ Mothers' treatment patterns } & \\
\cline { 3 - 5 } & & Democratic pattern & authoritarian pattern & Leisure pattern \\
\hline \multirow{2}{*}{ Emotional balance scale } & correlation coefficient & $.420^{* *}$ & $.464-* *$ & $.190-* *$ \\
& Statistical significance & .000 & .000 & .008 \\
& The number of sample members & 195 & 195 & 195 \\
\hline
\end{tabular}

The results of Table 6 revealed the following:

- There is a positive, statistically significant correlation at the significance level $(\alpha=0.05)$ between the total score of the emotional balance scale for kindergarten children and the democratic treatment pattern of mothers, where the correlation coefficient is $* * 0.420$, and with statistical significance $(0.000)$.

- There is a statistically significant negative correlation at the significance level $(\alpha=0.05)$ between the total score of the emotional balance scale for kindergarten children and the authoritarian treatment pattern of mothers, where the correlation coefficient is $* *-0.464$, with statistical significance $(0.000)$.

- There is a statistically significant negative correlation at the level of significance $(\alpha=0.05)$ between the total score of the emotional balance scale for kindergarten children and the type of parental treatment of mothers, where the correlation coefficient reached ${ }^{*} *_{-}-0.190$, with statistical significance $(0.008)$.

The researchers attribute this logical result and the closest to the different theoretical interpretations that the most important psychological and emotional balance sources are the methods of proper upbringing based on democracy, dialogue, reinforcement, acceptance, and allowing expression of opinion. It enables the child to understand his emotions and the emotions of others, which leads to his natural growth, which ultimately leads to psychological and emotional balance. Therefore, a positive correlation appeared between the total score of the emotional balance scale for kindergarten children and the democratic treatment pattern of mothers. On the other hand, as for the abnormal treatment methods represented by domination, idleness, and the lack of positive dialogue with children, they create an anxious and unbalanced personality, emotionally and psychologically, and weaken the children's sense of psychological security, especially at this critical stage of the child's life, which requires the child's feeling of trust, love, and containment, allowing them more freedom to express their feelings and emotions. Therefore, a negative correlation appeared between the total degree of the emotional balance scale for kindergarten children and the two types of mothers' authoritarian and abusive treatment.

This result agreed with the study of Ibriem (2011), whose results revealed a negative correlation between the children's perception of the father's treatment methods (discrimination, control, fluctuation) and their sense of psychological security. And there is a positive correlation between the children's awareness of the proper treatment method and their sense of psychological security. It also agreed with Al-Ghadani's (2014) study, whose results revealed a negative relationship between the methods of abnormal treatment as perceived by children and emotional balance. As well as with the study of Al-Tamawi (2017), the results of which revealed a negative relationship between emotional balance and negative parental treatment methods, and with the study of AlKhouribi (2002), the results of which revealed a positive correlation between the methods of normal treatment represented by democracy and the level of emotional balance among children of both sexes. It also agreed with the study of Al-Qaisi (2020), the results of which found a negative relationship between the methods of parental upbringing (chaotic, authoritarian) and emotional balance among the sample members, as well as the existence of a positive relationship between the method of democratic upbringing and emotional balance. Finally, it agreed with Sherrab's (2019) study in the presence of a significant positive correlation between family climate and psychological security and a significant negative correlation between family climate and electronic violence on the one hand and psychological safety on the other hand.

The results of the fourth question and its discussion: To what extent do mothers' treatment patterns contribute to the emotional balance of kindergarten children?

To answer this question and determine the extent to which mothers' treatment patterns contribute to the emotional balance of kindergarten children, multiple regression analysis was used according to the stepwise method. According to this method, the dimensions are arranged according to the strength of their interpretation from high to low, and variables or dimensions that have no statistical significance and their correlation or predictability are weak, and Table 7 shows this: 
Table 7. Results of multiple regression analysis to determine the extent to which mothers' treatment patterns contribute to the emotional balance of kindergarten children

\begin{tabular}{|c|c|c|c|c|c|c|c|c|}
\hline Predictor & $\begin{array}{l}\text { Interpreted } \\
\text { predictive } \\
\text { variables } \\
\end{array}$ & $\begin{array}{l}\text { correlation } \\
\mathbf{R}\end{array}$ & $\begin{array}{l}\text { The coefficient of } \\
\text { determination } \\
\text { R2 }\end{array}$ & $\begin{array}{l}\text { F. } \\
\text { value }\end{array}$ & $\begin{array}{l}\text { Statistical } \\
\text { significance } \\
\text { F } \\
\end{array}$ & $\begin{array}{l}\text { Beta } \\
\text { value }\end{array}$ & T Value & $\begin{array}{l}\text { Statistical } \\
\text { significance T }\end{array}$ \\
\hline \multirow[t]{6}{*}{$\begin{array}{l}\text { emotional } \\
\text { balance }\end{array}$} & $\begin{array}{l}\text { authoritarian } \\
\text { pattern }\end{array}$ & .464 & .215 & 53.014 & .000 & $.485-$ & $6.890-$ & .000 \\
\hline & stippling pattern & .571 & .326 & 46.393 & .000 & $.270-$ & $3.852-$ & .000 \\
\hline & Democratic pattern & .585 & .342 & 33.125 & .000 & .157 & 2.184 & .030 \\
\hline & \multicolumn{8}{|c|}{ Predictors (steady regression): authoritarian pattern } \\
\hline & \multicolumn{8}{|c|}{ Predictors (steady regression): authoritarian mode, passive mode } \\
\hline & \multicolumn{8}{|c|}{ Predictors (constant regression): authoritarian pattern, lethargic pattern, democratic pattern } \\
\hline
\end{tabular}

The results of Table 7 revealed that the contribution of mothers' treatment patterns to the emotional balance of kindergarten children was $34.2 \%$, whereas the overall determination coefficient (R2) for the patterns was 0.342 . This percentage was distributed among the three mothers' treatment patterns, respectively, from highest to lowest, as follows: (authoritarian pattern, laissez-faire pattern, and democratic pattern). The patterns of mothers' treatment contributed in varying proportions to the emotional balance of kindergarten children, as the correlation $(\mathrm{R})$ value of these patterns was $0.464,0.571$, and 0.585 , and the coefficient of the determination reached (R2) for these dimensions, respectively $0.215,0.326$, and 0.342 , and the (F) value was statistically significant, and its significance was 0.000 . The results also showed that the most prominent patterns of mothers' treatment that contributed to the emotional balance of kindergarten children was the authoritarian treatment pattern, where the value of $(\mathrm{t})$ was 6.890 , with statistical significance 0.000 , the value of Beta was -0.485 , and this dimension explained the rate of $21.5 \%$ in the change in emotional balance among kindergarten children. Then came the quiescent pattern, where the value of ( $t$ ) was -3.852 , with statistical significance 0.000 , and the value of Beta was -0.270 , where the authoritarian pattern added a percentage of $11.1 \%$ to make the coefficient of determination R2 0.326 , and finally the democratic pattern came, where the value of $(t)$ was 2.184 , with a statistical significance 0.030 , and the value of (Beta) was 0.157 , where the quiescent pattern added $0.016 \%$ to become the value of the coefficient of determination R2 0.342 . This result indicates that the extent to which mothers' treatment patterns contribute to the emotional balance of kindergarten children was $34.2 \%$. The remaining percentage is due to factors and institutions other than the family, such as kindergarten, peers and the media, and other social interactions, and all patterns contributed in varying proportions to the emotional balance of kindergarten children. The highest was the authoritarian pattern, perhaps because strictness in upbringing and excessive control in this age stage teach children the standards of acceptable and unacceptable behavior, right and wrong, which is reflected in the child's emotional balance. The idleness pattern also contributed to the child's emotional balance, as idleness gives the child an opportunity to learn on his own, solve his problems, and deal with the situations he faces alone. Also, the democratic pattern contributed to the child's emotional balance, in that the method of upbringing based on dialogue, acceptance, and guidance develops emotional balance in children. This result partially agreed with the study of Al-Badrin (2012), Al-Fraihat and Al-Muqabala (2017), and Sharab (2019).

\section{Recommendations}

- Direct mothers towards proper methods in raising their children,

- Deepening parents' understanding of the dangers of improper methods in raising their children,

- Kindergarten interest in the psychological and emotional aspects of children, which is reflected in their psychological balance,

- Pay attention to the kindergarten children segment and focus on it in studies.

- Conduct more studies on other variables that contribute to children's emotional balance.

\section{References}

Abbara, H., Rahal, M., \& Musa, A. (2019). Emotional balance and its relationship to academic problems among secondary school students in the city of Homs in Syria. Al-Quds Open University Journal for Educational and Psychological Research and Studies.

Abdeen, M. (2010). Parental attitudes in the social upbringing of young people as perceived by students of the second year of secondary school in the southern West Bank. The Jordanian Journal of Educational Sciences.

Abdel, M. A. (2015). Parental Treatment Methods Scale. Joanna for Publishing and Distribution, Egypt. 
Abu, I. S. (2002). Methods of parental treatment as perceived by children and their relationship to behavior disorder. Published MA thesis, The Islamic University, Gaza.

Abu, J. S. (2020). The Psychology of Socialization (14th ed.). Dar Al Masirah for Publishing and Distribution, Amman.

Abu, M. S. (2015). Psychological stress and its relationship to emotional balance and decision-making ability among emergency nurses in government hospitals. Unpublished Master's thesis, College of Education, Islamic University, Gaza.

Abu, S. H. (2017). The effect of the Montessori method in improving the listening and speaking skills of a kindergarten child. Dar Amjad for Publishing and Distribution, Amman, Jordan.

Abu, Z. A. (2009). The basics of psychological and educational counseling. Dar Al-Manhal.

Abu, Z. J. (2010). The emotional intelligence of outstanding students in the light of some variables. Journal of Psychological and Educational Sciences.

Agrawa, N., \& Kehksha, L. (2015). Religiosity as a predictor of Emotional Stability among Adolescence. The International Journal of Indian Psychology, 2(4), 183-188. https://doi.org/10.25215/0204.057

Al Yamani, A. (2014). Social, Emotional, and Moral Development in Children (Theories and Topics). Amman, Jordan.

Al-Badarin, G. (2012). Parenting patterns, identity patterns, and psychological adaptation as predictors of academic self-efficacy among Hashemite University students. The Jordanian Journal of Educational Sciences.

Al-Fraihat, A., \& Al-Muqabala, N. (2017). The predictive ability of the family communication environment, social, emotional, and academic self-efficacy with cognitive flexibility among tenth-grade students in Ajloun Governorate, Al-Quds Open University. Journal for Educational and Psychological Research and Studies.

Al-Ghadani, N. (2014). Methods of parental treatment as perceived by children and their relationship to emotional balance among verbally disturbed children in the Governorate of Muscat. Published Master's thesis, University of Nizwa, Oman.

Al-Khamaiseh, O. (2018). Levels of emotional stability among students of applied psychology at Princess Rahma University College in the light of the family's average monthly income variable. University of Applied Sciences, Amman.

Al-Khouribi, H. (2002). Methods of parental treatment as perceived by children of both sexes and their relationship to emotional balance in the age group (14-17) years. Unpublished Master's thesis, Ain Shams University, Cairo, Egypt.

Al-Mashi, M. (2009). Socialization and its relationship to personality estimation among a sample of delinquents and non-delinquents in the Jazan region. Unpublished Ph.D. thesis, Umm Al-Qura University, Saudi Arabia.

Al-Mohtaseb, A. (2012). Eating Disorders in Adolescents in Jordan and its Relationship to the Mother's Food Habits, Family Conflicts, and Media Influence. Unpublished Master's Thesis, University of Jordan, Amman.

Al-Qaisi, L. (2020). Psychological Balance and its Relationship to Parental Upbringing Methods. Journal of the Islamic University of Educational and Psychological Studies.

Al-Rabee, F., \& Attia, R. (2016). Emotional stability and its relationship to self-control among Yarmouk University students. Journal of Studies in Educational Sciences.

Al-Rawahieh, J. (2016). Parental treatment methods as perceived by the twelfth-grade students and their relationship to psychological adjustment in Al-Dakhiliyah Governorate. Published Master's thesis, University of Nizwa, Oman.

Al-San'ani, A. (2009). The relationship between psychological alienation and parental treatment methods for hearing-impaired students in the secondary stage. Published Master's thesis, Taiz University, Yemen.

Al-Sebaawi, F. (2010). Social shyness and its relationship to parenting patterns (1st ed.). Jordan: Safaa for Publishing and Distribution.

Al-Shara'a, N., \& Al-Momani, H. (2019). Patterns of socialization in the Jordanian family and their relationship to social, economic and cultural factors. Social and Human Sciences Studies.

Amara, S., \& Bouisha, N. (2013). Family dialogue and its relationship to emotional balance among adolescents, 
a field study of a sample of adolescents in the fourth intermediate sections in the Wilayat of Ouargla, the Second National Forum, Kasdi Merbah, and Ouargla University. Faculty of Humanities and Social Sciences, Algeria.

Asep, M., Tukimin, S., \& Fitria, N. (2021). The Relationship between Parenting Pattern and the Emotional Dynamics of Parents, and the Social Interactions of Mentally Retarded Children in Bahagia Foundation Special School in Tasikmalaya (pp. 415-428). The 4th International Virtual Conference on Nursing, KnE Life Sciences. https://doi.org/10.18502/kls.v6i1.8631

Attia, F. (2016). Emotional stability and its relationship to self-control among Yarmouk University students. Educational Sciences Studies.

Belkheir, A. (2020). Parental treatment methods and their relationship to self-esteem among fourth-grade students. Published Master's thesis, Ahmed Deraya University, Algeria.

Benhamou, J. (2018). Parental treatment methods and their relationship to adolescent psychological adjustment in secondary education. Unpublished Master's thesis, the Mohamed Khider University of Biskra in Algeria.

Bukakke, D., \& Daehler, ̈. (1992). Child Development (1 ed.). Boston: Houghton muffin.

Costa, S., Soenens, B., Gugliando, M. C., Cuzzocrea, F., \& Larcan, R. (2015). The Mediating Role of Need Satisfaction in Associations Between Parental Psychological Control and internalization Problems: A Study among Italian College Students. Journal of Child Family Studies, 24, 1106-1116. https://doi.org/10.1007/s10826-014-9919-2

El-Tamawy, E. (2020). Methods of parental treatment and its relationship to psychological adjustment among adolescent sons of secondary school students. The Egyptian Journal of Psychological Studies.

Fornells, H., \& Cooper, C. (2015). Patterns of interaction in family relationships and the Emotional balance in adolescence. Journal of Personality and Individual Differences, 14(6), 315-328.

Grotevant, P. (2013). Emotional balance: as a predictor of subsequent academic achievement. Journal of Psychotherapy in Australia, 22(4), 48-55.

Hamad, N. (2019). Measuring emotional balance among university students. College of Education, University of Baghdad, Ibn Rushd for Human Sciences.

Hamdan. (2010). Emotional equilibrium and its relationship to making decisions. Published Master's thesis, College of Education, Islamic University, Gaza.

Hamdan, K. (2010). Emotional stability and decision-making ability among Palestinian police officers. Unpublished Master's thesis, International Islamic Science University, Gaza.

Hassan, H. (2008). Methods of parental treatment as perceived by adolescents and their relationship to levels of psychological identity in Acre District, Palestine. Unpublished Master's thesis, Amman Arab University for Graduate Studies, Amman, Jordan.

Hurlock, K. (2010). The relation of nervous - emotional stability to educational achievement. Journal of Educational Psychology, 6(8), 429-440.

Ibriem, S. (2011). Methods of treating the father as perceived by the children and their relationship to the feeling of psychological security among a sample of secondary school students in the city of Tebessa. An-Najah University Journal for Research.

Kazlit, M. (2007). Parental treatment patterns and their relationship to behavioral disorders. Al-Safa Mental Health Forums. Retrieved from http://www. Elsa. Com Abu/show thread. pup

Khader, F. (2012). Rebellion and its relationship to parenting patterns among Al-Azhar University students. Master's thesis, College of Education, Al-Azhar University, Gaza.

Kumar. P. (2013). A Study of Emotional Stability and Socio- Economical- Status of Students Studying in Secondary Schools. International Journal of Education and Information Studies, 3(1), 7-11.

Losel, F., \& Bender, D. (2011). Emotional and Antisocial Outcomes of Bullying and Victimization at School: A Follow-Up from Childhood to Adolescence. Journal of Aggression, Conflict, and Peace Research, 3, 89-96. https://doi.org/10.1108/17596591111132909

Maciel, M., Nancy, E., Carlos, V., Tracy, L., Rebecca, H., Sarah, K., ... Kassondra, M. (2018). Balance in Positive Emotional Expressivity Across School Contexts Relates to Kindergartners' Adjustment. Early Education and Development, 29(1), 1-13 https://doi.org/10.1080/10409289.2017.1364946 
Mahrez, N. (2003). Parental treatment methods and their relationship to the child's social and personal compatibility in kindergarten. Damascus University Journal.

Makhout, F. (2014). Parental treatment methods for outstanding adolescents with a certificate of intermediate education. Published Master's thesis, the University of Mohamed Khider in Biskra, Algeria.

Mousa, S. (2019). A training program for developing soft skills for kindergarten teachers to improve communication with children and consider their requirements. Journal of Studies in Childhood and Education, $1(8), 1-64$.

Rayan, M. (2006). Emotional balance and its relationship to cognitive speed and innovative thinking among eleventh-grade students in Gaza Governorate. Published Master's thesis, Al-Azhar University, Gaza.

Revert, G. (2010). Assertiveness training for disabled adults in wheelchairs: Self-report, role-play, and activity pattern outcomes. Journal of Consulting and Clinical Psychology, 22(10), 419-425.

Robert, B., \& William, P. (2017). Teacher Assessment of Aggression by children in kindergarten, Ontario, Canada. Retrieved from ScienceDirect database.

Sabah, J. (2016). Patterns of family upbringing and their relationship to achievement motivation among students of the University of Muhammad Khider of Biskra. Published Ph.D. thesis, University of Muhammad Khider, Biskra.

Samour, A. (2012). Contrasting and its relationship to the emotional balance of eleventh-grade students. Published Master's Thesis, The Islamic University, Gaza.

Serebryakova, A., Morozavo, B., Kochnevaa, M., Zharova, V., Kopatternva, A., \& Kolarkova, G. (2016). Emotional Stability as Condition of students Adaptation to studying in a Higher Education. International Journal of Environmental \& Science Education, 7486-7494.

Shurrab, A. (2019). The predictive ability of family climate and psychological security on electronic violence among the age group between 14-16 years in Khan Yunis governorate in Gaza. University of Sharjah Journal of Humanities and Social Sciences.

Yagnik, I. (2013). Children of working and non-working women-awareness of responsibilities, emotional balance, family adjustment, proud of mother and expectations from mother a study. Annual International Conference on Cognitive \& Behavioral Psychology, 13-17. https://doi.org/10.5176/2251-1865_CBP13.12

Yasmina, A. (2018). Parental treatment methods and their relationship to the self-esteem of adolescent sons. Wartla University, Algeria.

Yildirim, S., \& Ayas, T. (2020). Examination of the Relationship among Adolescents' Subjective Wellbeing, Parenting Patterns with Smartphone in Terms of Different Variables. International Journal of Psychology and Educational Studies, 7(1), 61-75. https://doi.org/10.17220/ijpes.2020.01.006

Younes, A. (2015). Methods of parental treatment and its relationship to the self-confidence of the kindergarten child. Published Master's thesis, King Faisal University, Saudi Arabia.

Zaghoul, R., Alawneh, S., Al-Atoum, A., Al-Zaghoul, I., Al-Rimawi, M., Al-Tal, S., ... Al-Salti, N. (2014). General Psychology (5th ed.). Amman: Dar Al Masirah for Publishing and Distribution.

Zughayer, L. (2007). Self-confidence and its relationship to parenting methods. Journal of Educational and Psychological Research Center.

\section{Copyrights}

Copyright for this article is retained by the author, with first publication rights granted to the journal.

This is an open-access article distributed under the terms and conditions of the Creative Commons Attribution license (http://creativecommons.org/licenses/by/4.0/). 